\title{
Plasmodium spp.'nin Saptanmasında Multipleks Nested PCR, In-house Gerçek Zamanlı PCR ve Ticari Gerçek Zamanlı PCR Yöntemlerinin Karşılaştırılması
}

\section{Comparison of Multiplex Nested PCR, In-house Real-Time PCR and Commercial Real-Time PCR Methods for the Detection of Plasmodium spp. from Blood Samples}

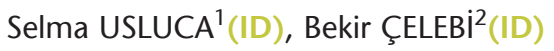 \\ 1 T.C. Halk Sağlığı Genel Müdürlüğü, Mikrobiyoloji Referans Laboratuvarları ve Biyolojik Ürünler Daire Başkanlığı \\ Ulusal Parazitoloji Referans Laboratuvarı, Ankara. \\ ${ }^{1}$ General Directorate of Public Health, Department of Microbiology Reference Laboratories and Biological Products, \\ Ankara, Turkey. \\ 2 T.C. Halk Sağlığı Genel Müdürlüğü, Zoonotik ve Vektörel Hastalıklar Daire Başkanlığı, Ankara. \\ ${ }^{2}$ General Directorate of Public Health, Department of Zoonotic and Vector-borne Diseases, Ankara, Turkey.
}

Makale Atıfı: Usluca S, Çelebi B. Plasmodium spp.'nin saptanmasında multipleks nested PCR, in-house gerçek zamanlı PCR ve ticari gerçek zamanlı PCR yöntemlerinin karşılaştırılması. Mikrobiyol Bul 2020;54(2):306-317.

\section{ÖZ}

Sıtma, Plasmodium cinsi parazitlerin etken olduğu yaşamı tehdit edebilen paraziter bir hastalıktır. Giemsa boyalı kan yaymasının mikroskobik incelemesi tanıda altın standart yöntem olarak kabul edilmektedir. Tüm dünyada olduğu gibi ülkemizde de önemli bir sağlık sorunu olan sıtmanın laboratuvar tanısını güçlendirebilmek için birden fazla yöntemin bir arada kullanılması önerilmektedir. Bu çalışmada, üç farkı moleküler yöntemin sonuçlarının karşılaştıııması ve uygulanacak tanı algoritmasında hangi moleküler yöntemin kullanılacağının belirlenmesi amaçlanmıştır. Sıtma şüphesiyle laboratuvarımıza gönderilen 280 adet EDTA'lı tüpte saklanan tam kan örneğine ticari kit kullanılarak DNA ekstraksiyonu yapılmış ve elde edilen DNA örneklerinde Plasmodium spp.'nin saptanmasında üç farklı polimeraz zincir raksiyonu (PCR) yöntemi kullanılarak sonuçlar karşılaştırıımıştır. ilk olarak multipleks nested PCR, ardından da laboratuvarımızda doğrulanmış olan in-house gerçek zamanlı PCR (Rt-PCR) ve ticari bir kit ile Rt-PCR yöntemleri uygulanmıştır. Multipleks nested PCR yöntemi altın standart olarak kabul edilmiş ve Plasmodium spp. açısından pozitif olarak değerlendirilen 182 örnek ile, negatif olarak değerlendirilen 98 örnek, in-house ve ticari Rt-PCR yöntemleriyle de çalışılmıştır. Multipleks nested PCR yönteminin birinci basamak reaksiyonunda Plasmodium spp. pozitif örneklerde 1670 baz çifti (bp), ikinci basamak reaksiyonunda Plasmodium vivax pozitif örneklerde 117 bp bant gözlenmiştir. In-house Rt-PCR'de erime eğrisi analizi ile P.vivax pozitif örneklerin Tm değerleri 78-79 olarak belirlenmiştir. In-house Rt-PCR yöntemi ile pozitif örneklerin CT değerleri 20.03-31.71 arasında, ticari Rt-PCR yöntemi ile pozitif örneklerin CT değerleri ise 17.26-34.94

Iletişim (Correspondence): Dr. Selma Usluca, T.C. Halk Sağlığı Genel Müdürlüğü, Ulusal Mikrobiyoloji Referans Laboratuvarları ve Biyolojik Ürünler Daire Başkanlığı, Adnan Saygun Caddesi No: 55, 06100, Sihhiye, Ankara, Türkiye. Tel (Phone): +90 505253 7123, E-posta (E-mail): selmausluca@gmail.com 
arasında saptanmıştır. In-house Rt-PCR yöntemi ile olguların $180^{\prime} \mathrm{i}$, ticari Rt-PCR yöntemi ile olguların 178 'i pozitif olarak belirlenmiştir. In-house Rt-PCR ile 2 örnek, ticari Rt-PCR ile 4 örnek yalancı negatif olarak değerlendirilmiştir. Her iki yöntemin duyarlılık ve özgüllükleri hesaplandığında in-house Rt-PCR yönteminin duyarlılı̆ı 0.98 , özgüllüğü 0.97 , pozitif prediktif değeri (PPD) $\% 98$, negatif prediktif değeri (NPD) \%97 olarak, ticari Rt-PCR yönteminin duyarlılığı 0.97, özgüllüğü 0.95, PPD \%97, NPD \%95 olarak belirlenmiştir. In-house ve ticari Rt-PCR yöntemleri arasında yüksek düzeyde uyum (к: 0.953 ) belirlenmiştir. Bir testin doğrulama testi olarak kabul edilmesi için özgüllüğünün yüksek olması gereklidir. Çalışmamızın sonucunda in-house Rt-PCR yönteminin saptanan duyarlılık ve özgüllüğünün Plasmodium türlerinin laboratuvar tanısında yöntemin kullanımına uygun olduğu düşünülmüştür.

Anahtar kelimeler: Sıtma; Plasmodium spp.; multipleks nested PCR; gerçek zamanlı PCR.

\section{ABSTRACT}

Malaria is a life-threatening parasitic disease caused by the parasites belonging to Plasmodium genus. Microscopic examination of Giemsa stained blood smears is accepted as the gold standard diagnostic method. It is recommended to use more than one method in order to strengthen the laboratory diagnosis of malaria which is an important health problem in our country as in the whole world. In this study, it was aimed to compare the results of three different molecular methods and determine which molecular method could be used in the diagnostic algorithm to be applied. DNA was extracted from 280 whole blood sample stored in EDTA tubes using a commercial kit. Three different polymerase chain reaction (PCR) methods were used for the detection of Plasmodium spp. in DNA samples obtained and the results were compared. First, multiplex nested PCR was applied and then in-house real-time PCR (Rt-PCR) which was validated in our laboratory and a commercial Rt-PCR kit were applied. Multiplex nested PCR was accepted as the gold standard and 182 samples that were evaluated as Plasmodium spp. positive and 98 samples that were evaluated as negative were also studied by in-house and commercial Rt-PCR methods. In multiplex nested PCR's first step reaction 1670 base pairs (bp) band was observed in Plasmodium spp. positive samples and $117 \mathrm{bp}$ band was observed in Plasmodium vivax positive samples in the second step reaction. Tm values of P.vivax positive samples were determined as 78-79 in the melting analysis of the in-house Rt-PCR. CT values of the positive samples in in-house Rt-PCR were between 20.03-31.71 and were between 17.26-34.94 in the commercial Rt-PCR. With the in-house Rt-PCR method 180 cases were determined as positive, while with the commercial Rt-PCR method 178 cases were determined as positive. Two samples with the in-house Rt-PCR and 4 samples with the commercial Rt-PCR were considered as false negative. When the sensitivity and specificity of the both methods were calculated, the sensitivity of the in-house Rt-PCR method was 0.98 , the specificity was 0.97 , the positive predictive value (PPV) was $98 \%$, the negative predictive value (NPV) was $97 \%$, the sensitivity of the commercial Rt-PCR was 0.97 , the specificity was 0.95 , the PPV was $97 \%$, the NPV was $95 \%$. A high level of agreement ( $\kappa: 0.953$ ) was determined between the in-house and the commercial Rt-PCR methods. In order for a test to be accepted as a confirmatory test, its specificity must be high. It was decided that sensitivity and specificity of the in-house Rt-PCR were suitable for using this method in the laboratory diagnosis of Plasmodium species.

Keywords: Malaria; Plasmodium spp.; multiplex nested PCR; real-time PCR.

\section{Gíriş}

Sıtma, Plasmodium cinsi parazitlerin etken olduğu yaşamı tehdit edebilen paraziter bir hastalıktır. Plasmodium falciparum, Plasmodium vivax, Plasmodium ovale, Plasmodium malariae, Plasmodium knowlesi olmak üzere insanı enfekte eden beş türü bilinmektedir. P.falciparum en yüksek mortalite oranına neden olan tür iken, P.vivax düşük mortaliteye yol açmakta ve ılımlı bir klinik seyir gözlenmektedir ${ }^{1}$. P.vivax ve P.ovale türleri kronik karaciğer evresi (hipnozoit) oluşturabilmekte ve nüks enfeksiyona neden olabilmektedirler $^{2}$. Ülkemizde görülebilen etken tür P.vivax olmakla birlikte diğer türler ile yurt dışı 
kaynaklı sporadik olgular da bildirilmektedir",3. Türkiye 1957 yılında "Ulusal Sıtma Eradikasyonu Programı"na dahil edilmiş ve ciddi bir sıtma ile savaş programı uygulanmıştır. 1983 yılında eradikasyon programı "Sıtma Kontrol Programı" olarak değiştirilmiş, 2006 yılında da ülkemiz eliminasyon programına dahil edilmiştir ${ }^{4}$.

Aralarında ülkemizin de bulunduğu 16 ülkede (Arjantin, Ermenistan, Azerbaycan, Kosta Rika, Irak, Gürcistan, Kırgızistan, Fas, Umman, Paraguay, Sri Lanka, Tacikistan, Türkmenistan, Birleşik Arap Emirlikleri, Özbekistan) 2014 yılında sıfır yerli olgu bildirilmiştir ${ }^{5}$.

Giemsa boyalı kan yaymalarının mikroskobik incelemesi sıtma tanısında halen altın standart yöntem olarak kabul edilmektedir. Ancak, bu yöntemin kısıtlıığı, hazırlanan preparatın ve boyamanın kalitesi, değerlendirme süresi gibi birçok faktöre bağlı olarak tecrübeli laboratuvar personeli tarafından uygulandığında bile tanının atlanabilmesidir. Artan ilaç direncine karşılık daha pahalı antimalaryal kombinasyon tedavileri uygulandığı için hızlı ve doğru tanı araçlarına duyulan gereksinim giderek daha fazla önem kazanmaktadır 6 .

Sıtma ülkemizde elimine edilmiş olmakla birlikte, hastalığın endemik olarak görüldüğü bir coğrafi bölgede yer alması ve son yıllarda diğer endemik bölgelerden çok sayıda göç alması nedeniyle laboratuvar tanısını güçlendirebilmek için birden fazla yöntemin bir arada kullanılması önerilmektedir. Özellikle tanı problemi yaşanan düşük parazitemi oranına sahip olan veya kliniği sıtmayı düşündüren olgularda tanının doğrulanması gerekmektedir. Moleküler yöntemler bu gibi olgularda tanıya önemli katkı sağlamakla birlikte, duyarlılık ve özgüllükleri farklılık göstermektedir. Bu çalışmada, üç farklı moleküler yöntemin karşılaştırılması ve elde edilen sonuçlara dayanarak uygun olan yöntemin belirlenerek laboratuvarımıza sıtma şüphesi ile gelen kan örneklerine uygulanacak tanı algoritmasında hangi moleküler yöntemin kullanılacağının belirlenmesi amaçlanmıştır.

\section{GEREÇ ve YÖNTEM}

Bu çalışma, Ankara Eğitim ve Araştırma Hastanesi Klinik Araştırmalar Etik Kurulu onayı ile gerçekleştirildi (Tarih: 16.01.2020 ve Karar no: 158/2019).

Sıtma şüphesiyle Ağustos 2012-Ağustos 2013 tarihleri arasında Mardin ili Savur ilçesine bağlı Başkavak köyünden hastalığın tanısının doğrulanması amacıyla laboratuvarımıza gönderilen, mikroskobik olarak 182'si pozitif, 98'i negatif olmak üzere toplam 280 adet EDTÁlı tüpte saklanan tam kan örneğine ticari kit (QiAmp DNA Blood Kit, Qiagen, Almanya) kullanılarak üretici firmanın önerileri doğrultusunda DNA ekstraksiyonu uygulandı. Elde edilen DNA örneklerinde Plasmodium spp.'nin saptanması için 3 farklı polimeraz zincir reaksiyonu (PCR) yöntemi kullanıldı ve sonuçları karşılaştırıldı. İlk olarak Singh ve arkadaşlarının ${ }^{7}$ bildirdiği Plasmodium cinsine özgü rPLU1, rPLU5 primerleri ve türe özgü rVIV1, rVIV2, rFAL1, rFAL2, rMAL1, rMAL2, rOVA1, rOVA2 primerleri kullanılarak multipleks nested PCR yöntemleri uygulandı. Ardından laboratuvarımızda doğrulanmış bir yöntem olarak Mangold ve arkadaşlarının ${ }^{8}$ bildirdiği PL1473F18, PL1679R18 
primerleri kullanılarak in-house gerçek zamanlı PCR (Rt-PCR) ve ticari kit (Genesig, Primer Design, İngiltere) ile Plasmodium spp. primerleri (18S ribosomal RNA geni) kullanılarak tüm örneklere Rt-PCR yöntemi uygulandı. Ticari Rt-PCR yöntemi ile Plasmodium spp. pozitif sonuç elde edilen örneklere üretici firmanın önerileri doğrultusunda her bir Plasmodium alt türüne yönelik ticari kit ile (Genesig, Primer Design, İngiltere) PCR amplifikasyonu uygulandı. Multipleks nested PCR ve in-house Rt-PCR'de kullanılan primer dizileri Tablo I'de gösterilmiştir.

Multipleks nested PCR'nin birinci basamak amplifikasyonu için $50 \mu$ toplam hacim içerisinde $5 \mu$ DNA olacak şekilde karışım oranları; $5 \mu$ l Hotstart Taq tampon çözeltisi (Thermo Scientific, ABD), $4 \mu \mathrm{MgCl}_{2}$ (Thermo Scientific, ABD), $1 \mu \mathrm{l}$ dNTP (Thermo Scientific, $A B D$ ), birer $\mu \mathrm{l}$ (10 pmol) rPLU1 ve rPLU5 primerleri (Metabion, Almanya), $0.25 \mu \mathrm{l}$ Hotstart Taq DNA polimeraz enzimi (Thermo Scientific, ABD), $37.5 \mu$ distile su içerecek şekilde hazırlandı. İkinci basamak PCR amplifikasyonu için $20 \mu \mathrm{l}$ toplam hacim içerisinde $2 \mu \mathrm{l}$ amplikon olacak şekilde karışım oranları; $2 \mu$ l Hotstart Taq tampon çözeltisi (Thermo Scientific, ABD), $3 \mu \mathrm{MgCl}_{2}$ (Thermo Scientific, ABD), $0.5 \mu \mathrm{l}$ dNTP (Thermo Scientific, ABD), 0.5'er $\mu \mathrm{l}$ (10 pmol) rVIV1, rVIV2, rFAL1, rFAL2, rMAL1, rMAL2, rOVA1, rOVA2 primerleri (Metabion, Almanya), $0.1 \mu$ l Hotstart Taq DNA polimeraz enzimi (Thermo Scientific, ABD) içerecek şekilde hazırlandı. Amplifikasyon koşulları $95^{\circ} \mathrm{C}^{\prime}$ de 5 dakika başlangıç denatürasyonu, $95^{\circ} \mathrm{C} 30$ saniye, $52^{\circ} \mathrm{C} 1$ dakika, $72^{\circ} \mathrm{C} 1$ dakika olmak üzere 35 döngü, $72^{\circ} \mathrm{C} 5$ dakika son uzama şeklinde birinci basamak reaksiyon, $94^{\circ} \mathrm{C}^{\prime}$ de 4 dakika başlangıç denatürasyonu, $94^{\circ} \mathrm{C} 30$ saniye, $55^{\circ} \mathrm{C} 1$ dakika, $72^{\circ} \mathrm{C} 1$ dakika olmak üzere 35 döngü, $72^{\circ} \mathrm{C} 5$ dakika son uzama şeklinde ayarlanarak ikinci basamak reaksiyon gerçekleştirildi. Elde edilen amplifikasyon ürünleri \%1.5 agaroz jelde görüntülendi.

\begin{tabular}{ll}
\hline \multicolumn{2}{l}{ Tablo I. Multipleks Nested PCR ve In-house Rt-PCR Yöntemlerinde Kullanılan Primer Dizileri } \\
\hline Primer adı & Primer dizisi \\
\hline rPLU1 & 5'-TCA AAG AT TAA GCC ATG CAA GTG A-3' \\
rPLU5 & 5'-CCT GTT GTT GCC TTA AAC TTC-3' \\
r VIV 1 & 5'-CGC TTC TAG CTT AAT CCA CAT AAC TGA TAC-3' \\
r VIV 2 & 5'-ACT TCC AAG CCG AAG CAA AGA AAG TCC TTA-3' \\
r fAL 1 & 5'-TTA AAC TGG TTT GGG AAA ACC AAA TAT ATT-3' \\
r fAL 2 & 5'-ACA CAA TGA ACT CAA TCA TGA CTA CCC GTC-3' \\
r mal 1 & 5'-ATA ACA TAG TTG TAC GTT AAG AAT AAC CGC-3' \\
r mal 2 & 5'-AAA ATT CCC ATG CAT AAA AAA TTA TAC AAA-3' \\
r OVA1 & 5'-ATC TCT TTT GCT ATT TTT TAG TAT TGG AGA-3' \\
r OVA2 & 5'-GGA AAA GGA CAC ATT AAT TGT ATC CTA ATG-3' \\
PL1473 F & 5'-TAA CGA ACG AGA TCT TAA-3' \\
PL1679 R & 5'-GTT CCT CTA AGA AGC TTT-3' \\
\hline
\end{tabular}

PCR: Polimeraz zincir reaksiyonu, Rt-PCR: Gerçek zamanlı polimeraz zincir reaksiyonu. 
Çalışmada pozitif kontrol örneği olarak, laboratuvarın katılım sağladığı bir dış kalite kontrol programına ait örnekler kullanıldı. P.vivax pozitif kontrol örneğinde 117 baz çifti (bp), P.falciparum pozitif kontrol örneğinde 205 bp, P.malariae pozitif kontrol örneğinde 144 bp, P.ovale pozitif kontrol örneğinde 787 bp bant gözlendi. Laboratuvarımızda mikroskopi ve PCR ile P.vivax pozitif olarak saptanan ve dizi analizi yapılan bir kan örneğinden ticari kit ile (QIAmp DNA mini blood kit, Qiagen, Almanya) DNA ekstraksiyonu yapıldı. Elde edilen DNA örneği plazmite klonlandıktan sonra plazmit ekstraksiyonu yapılarak DNA ölçümü gerçekleştirildi. Bu DNA örneğinden 1/10 oranında hazırlanan seri dilüsyonlarla saptama limiti çalışması yapıldı.

In-house Rt-PCR amplifikasyonu için $20 \mu \mathrm{l}$ toplam hacim içerisinde $2 \mu \mathrm{l}$ DNA olacak şekilde karışım oranları; $10 \mu \mathrm{l}$ EvaGreen mastermix (Biotium, ABD), birer $\mu \mathrm{l}$ (10 pmol) PL1473F18 ve PL1679R1 8 primerleri (Metabion, Almanya), $6 \mu$ listile su olacak şekilde hazırlandı. Amplifikasyon koşulları $95^{\circ} \mathrm{C}$ 'de 5 dakika başlangıç denatürasyonu, $95^{\circ} \mathrm{C} 10$ saniye, $50^{\circ} \mathrm{C} 30$ saniye, $72^{\circ} \mathrm{C} 20$ saniye olmak üzere 40 döngü şeklinde düzenlenerek gerçekleştirildi. Erime eğrisi analizi $68-95^{\circ} \mathrm{C}$ arasında değerlendirildi.

Ticari kit (Genesig, Primer Design, İngiltere) ile Plasmodium spp. primerleri kullanılarak üretici firmanın önerisi doğrultusunda Rt-PCR yöntemi uygulandı. In-house ve ticari Rt-PCR yöntemleri arasındaki uyumu istatistiksel olarak değerlendirmek için kappa testi kullanıldı.

\section{BULGULAR}

DNA ölçümü sonucunda plazmit DNA konsantrasyonu $57 \mathrm{ng} / \mu \mathrm{l}(2.4$ x 1010 kopya) olarak belirlenmiştir. Bu örnekten hazırlanan seri dilüsyonlarla çalışılan Rt-PCR yönteminde saptama limiti 10-9 (reaksiyonda 24 kopya) olarak tespit edilmiştir.

Multipleks nested PCR yöntemi altın standart olarak kabul edilmiş ve Plasmodium spp. açısından pozitif olarak değerlendirilen 182 örnek ile, negatif olarak değerlendirilen 98 örnek, ticari ve in-house Rt-PCR yöntemleriyle de çalışılmıştır. Pozitif olarak belirlenen örneklerin tümü P.vivax olup, mikst enfeksiyon saptanmamıştır. Elde edilen sonuçlar Tablo II'de verilmiştir.

Multipleks nested PCR ile birinci basamak reaksiyonda Plasmodium spp. pozitif örneklerde 1670 bp büyüklüğünde, ikinci basamak reaksiyonda P.vivax pozitif örneklerde 117 bp büyüklüğünde bant gözlenmiştir. İkinci basamak reaksiyonda Plasmodium türlerine ait pozitif örnekler Resim 1'de gösterilmiştir.

\begin{tabular}{|c|c|c|c|}
\hline Test sonucu & Ticari Rt-PCR & In-house Rt-PCR & Multipleks Nested PCR \\
\hline Pozitif & 178 & 180 & 182 \\
\hline Negatif & 102 & 100 & 98 \\
\hline Toplam & 280 & 280 & 280 \\
\hline
\end{tabular}




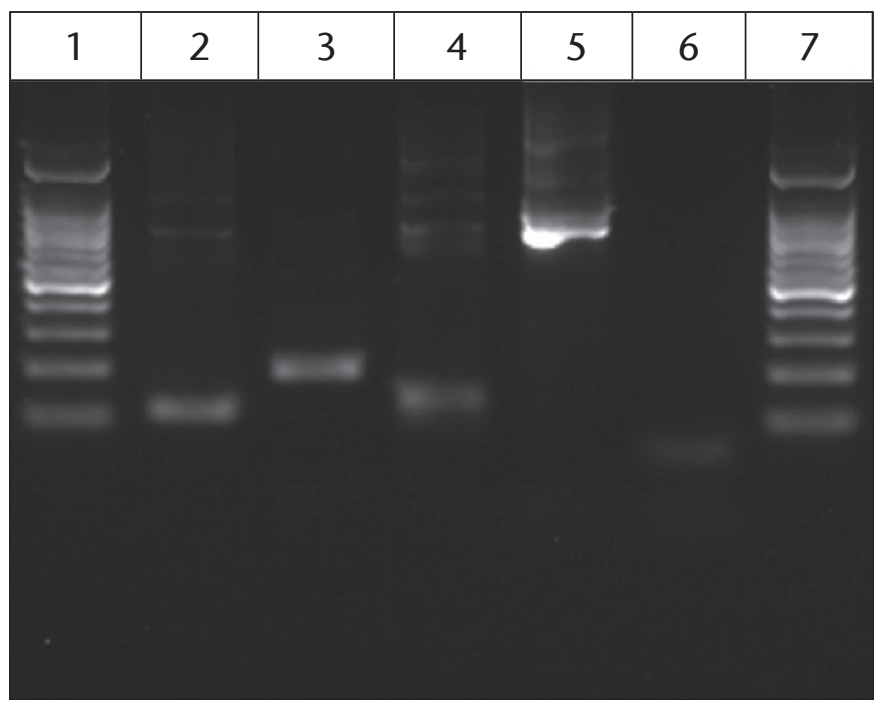

Resim 1. Multipleks nested PCR amplifikasyon ürünlerinin jel elektroforez görüntüsü. 1: 100 bp moleküler ağırlık belirteci. 2: P.vivax pozitif örnek (117 bp). 3: P.falciparum pozitif örnek (205 bp). 4: P.malariae pozitif örnek (144 bp). 5: P.ovale pozitif örnek (787 bp). 6: Negatif kontrol. 7: 100 bp moleküler ağırlık belirteci.

Buna göre P.vivax pozitif örnekte 117 bp, P.falciparum pozitif örnekte 205 bp, P.malariae pozitif örnekte 144 bp, P.ovale pozitif örnekte 787 bp büyüklüğünde bant elde edilmiştir. In-house Rt-PCR'de pozitif örnekler erime eğrisi analizi ile değerlendirilmiştir. P.vivax pozitif kontrol örneğinin Tm değerleri 78-79, P.falciparum pozitif kontrol örneğinin Tm değerleri 75-75.5, P.malariae pozitif kontrol örneğinin Tm değerleri 74-74.5, P.ovale pozitif kontrol örneğinin Tm değerleri 76.5-77 olarak belirlenmiştir (Şekil 1).

In-house Rt-PCR'nin CT değerleri 20.03-31.71 arasında saptanmıştır (Şekil 2).

Ticari Rt-PCR'nin CT değerleri ise 17.26-34.94 arasında saptanmıştır. In-house Rt-PCR yöntemi ile olguların 180 'i, ticari Rt-PCR yöntemi ile olguların 178'i pozitif olarak belirlenmiştir. In-house Rt-PCR ile 2 örnek (Tablo III), ticari Rt-PCR ile 4 örnek yalancı negatif olarak değerlendirilmiştir (Tablo IV).

In-house ve ticari Rt-PCR ile yalancı negatif olarak belirlenen 2 örnek aynı hastaya ait bulunmuştur. Ticari Rt-PCR ile 2 örnek daha negatif olarak belirlenmiştir. Her iki yöntemin duyarlılık ve özgüllükleri hesaplandığında in-house Rt-PCR yönteminin duyarlıığı 0.98, özgüllüğü 0.97, pozitif prediktif değeri (PPD) \%98, negatif prediktif değeri (NPD) \%97 olarak, ticari Rt-PCR yönteminin duyarlılığı 0.97, özgüllüğü 0.95, PPD \%97, NPD \%95 olarak belirlenmiştir. In-house ve Rt-PCR yöntemleri arasında yüksek düzeyde uyum (к: 0.953) belirlenmiştir (Tablo V). 


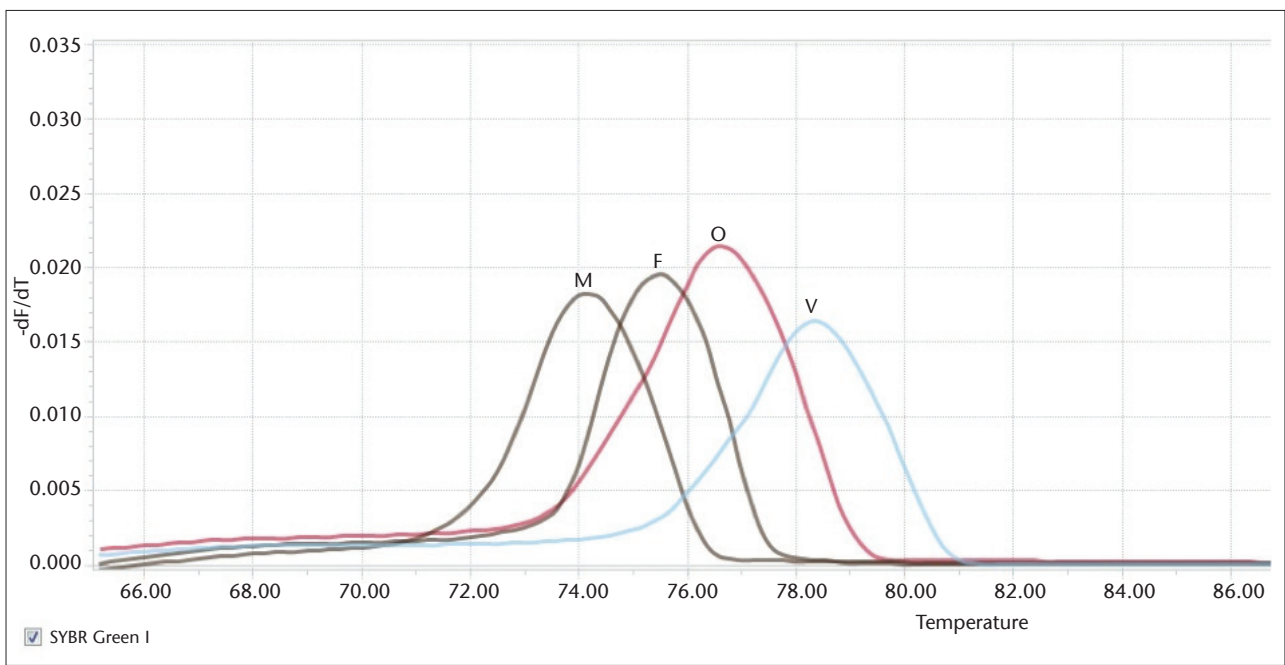

Şekil 1. In-house Rt-PCR erime eğrileri. M: P.malariae pozitif kontrol örneğinin erime eğrisini, F: P.falciparum pozitif kontrol örneğinin erime eğrisini, O: P.ovale pozitif kontrol örneğinin erime eğrisini, V: P.vivax pozitif kontrol örneğinin erime eğrisini göstermektedir.

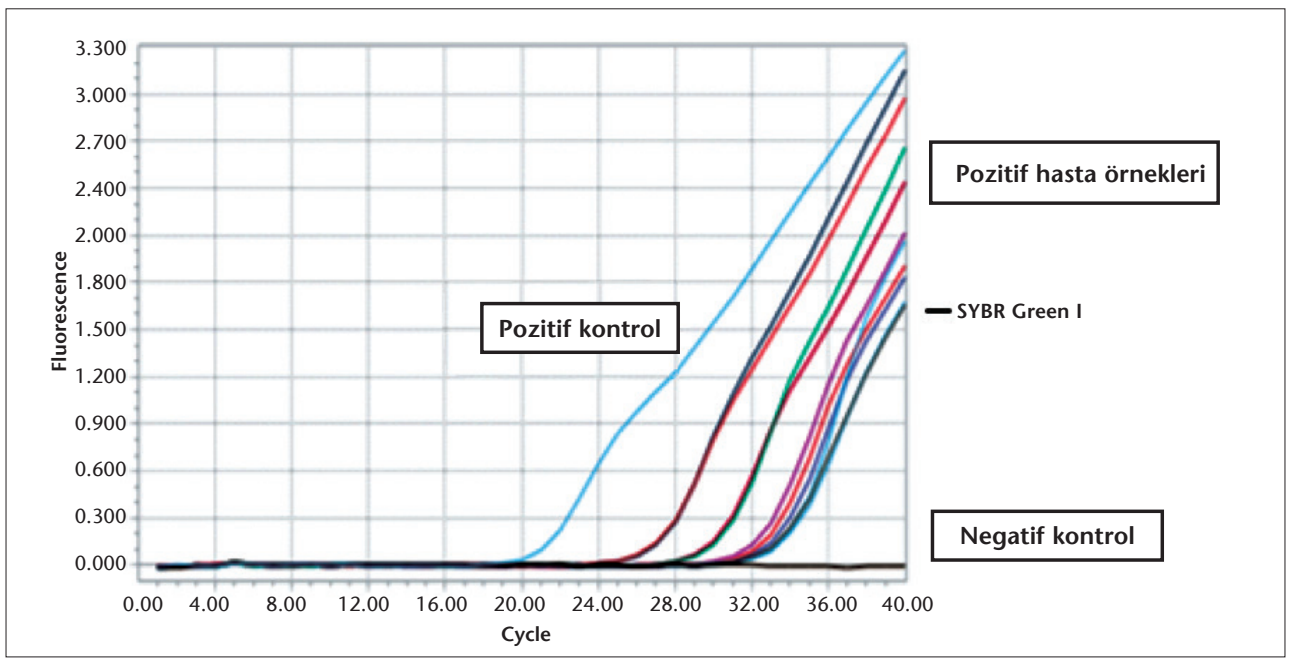

Şekil 2. In-house Rt-PCR amplifikasyon eğrileri.

Tablo III. In-house Rt-PCR Yönteminin Multipleks Nested PCR Yöntemiyle Karşılaştırmalı Sonuçları

\begin{tabular}{|c|c|c|c|c|}
\hline \multirow{5}{*}{ In-house Rt-PCR } & \multicolumn{4}{|c|}{ Multipleks Nested PCR } \\
\hline & & Pozitif & Negatif & Toplam \\
\hline & Pozitif & 180 & 2 & 182 \\
\hline & Negatif & 2 & 96 & 98 \\
\hline & Toplam & 182 & 98 & 280 \\
\hline
\end{tabular}

PCR: Polimeraz zincir reaksiyonu, Rt-PCR: Gerçek zamanlı polimeraz zincir reaksiyonu. 


\begin{tabular}{|l|cccc}
\hline \multicolumn{3}{|c|}{ Tablo IV. Ticari Rt-PCR Yönteminin Multipleks Nested PCR Yöntemiyle Karşılaştırmalı Sonuçları } \\
\hline \multirow{4}{*}{ Ticari Rt-PCR } & \multicolumn{4}{c}{ Multipleks Nested PCR } \\
\cline { 2 - 5 } & & Pozitif & Negatif & Toplam \\
\cline { 2 - 5 } & Pozitif & 178 & 4 & 182 \\
& Negatif & 4 & 94 & 98 \\
& Toplam & 182 & 98 & 280 \\
\hline
\end{tabular}

PCR: Polimeraz zincir reaksiyonu, Rt-PCR: Gerçek zamanlı polimeraz zincir reaksiyonu.

Tablo V. In-house Rt-PCR ile Ticari Rt-PCR Yönteminin Karşılaştırmalı Sonuçları

\section{In-house Rt-PCR}

\begin{tabular}{|c|c|c|c|c|}
\hline \multirow{5}{*}{ Ticari Rt-PCR } & \\
\hline & & Pozitif & Negatif & Toplam \\
\hline & Pozitif & 178 & 4 & 182 \\
\hline & Negatif & 2 & 96 & 98 \\
\hline & Toplam & 180 & 100 & 280 \\
\hline
\end{tabular}

PCR: Polimeraz zincir reaksiyonu, Rt-PCR: Gerçek zamanlı polimeraz zincir reaksiyonu.

\section{TARTIŞMA}

Sıtma tanısında referans yöntem kalın damla ve ince yayma preparatların mikroskobik incelemesidir ${ }^{2}$. Moleküler yöntemlerle karşılaştırıldığında mikroskobik inceleme maliyetetkin olmasına rağmen, değerlendiren kişinin deneyimi sonucu etkileyebilmektedir. Bu yöntem deneyimli personele gereksinim duymaktadır ve çok sayıda örneğin kısa sürede taranması için uygun değildir. Parazitemi düzeyi düşük örneklerde preparat hazırlığı hariç, değerlendirme süresi 45-90 dakikadır ${ }^{9}$. Bu süreyi kısaltmak için mikroskobik incelemenin yanı sıra hızı tanı testleri de kullanılmaktadır. Hızı tanı testleri, mikroskobik inceleme ile karşılaştırıldığında kolay uygulanabilir, hızlı sonuç verebilen yöntemlerdir. Ancak hızlı tanı testleri P.falciparum ve P.vivax'ı ayırt edebilmekte, P.malariae ve P.ovale' yi ayırt edememektedir ${ }^{2}$. Subklinik veya asemptomatik enfeksiyonlar sıtma endemik bölgelerde yaygın olup tanısı güçtür. Bu olgular, saptama limiti 50-100 parazit/ $\mu$ l olan mikroskobik inceleme ve/ veya hızı tanı testleri ile sıklıkla gözden kaçırılmakta, bu kişiler bulaştırıcı olmaya devam etmekte, sıtmanın eliminasyon çalışmalarına engel olmaktadır ${ }^{10}$. Mikroskobik inceleme ve hızlı tanı testlerinin bu dezavantajlarını ortadan kaldırmak için günümüzde moleküler yöntemler önem kazanmaktadır.

PCR yöntemi, hızlı tanı testleri ile saptanmasına rağmen tür ayrımı yapılamayan olgularda, P.falciparum dışındaki türlerle enfeksiyon veya mikst enfeksiyon durumlarında değerlidir ve tedavi takibinde tercih edilen bir yöntemdir ${ }^{11}$. Konvansiyonel ve Rt-PCR'nin de kısıtlılıkları ve birbirlerine üstünlükleri vardır. Konvansiyonel PCR yönteminin maliyetinin düşük olması nedeniyle Rt-PCR yerine kullanılabileceğini bildiren çalışmalar mevcuttur ${ }^{12}$. Nested PCR, spesifik ve duyarlı bir tanı yöntemi olmakla birlikte, sonuç verme süresinin 
uzun olması nedeniyle kullanımı kısıtlıdır ${ }^{13}$. Rt-PCR yöntemiyle örneğin hazırlanma süresi de dahil olmak üzere üç saat içinde sonuç bildirilebilmektedir ${ }^{2,12}$. Daha kısa sürede verilen hasta sonucu, tanı konulmamış ya da yanlış tanı konulmuş olguların hızlı bir şekilde belirlenebilmesi ve hasta yönetimine olumlu bir etki yapacaktır ${ }^{2}$. Rt-PCR ile, amplifikasyon sonrası DNA kontaminasyon riski düşüktür, parazitin kantitasyonu da yapılabilmektedir $^{12,13}$. Ancak bu yöntem, düşük parazitemi oranlarında yüksek duyarlılık gösterirken, mikst enfeksiyonların saptanmasında düşük duyarlılığa sahiptir. Mikst enfeksiyon durumlarında, düşük yoğunlukta görülen Plasmodium türlerinin DNA'sının saptanmasında primer rekabeti görülmektedir ${ }^{2}$. Parazitin tür ayrımı hastaların klinik yönetimi açısından kritiktir, çünkü tedavinin seyri enfeksiyona neden olan türe bağlı olarak değişmektedir ${ }^{8}$. PCR tekniğinin bir diğer dezavantajı başarısının, uygun olmayan kan örneği alma ve örnek saklama gibi faktörlerden etkilenebilecek DNA kalitesine dayanmasıdır .

Sıtma tanısında kullanılan moleküler yöntemler değerlendirildiğinde farklı primer setleriyle konvansiyonel, in-house ve ticari Rt-PCR yöntemlerinin karşılaştıııldığı birçok çalışmaya rastlanmaktadır. Bunlar arasında PL1473F18 ve PL1679R18 primerleri kullanılarak Plasmodium spp.'nin 18S rRNA geninin türe özgü bölgesini hedefleyen Rt-PCR yöntemi uygulanan çalışmaların yanı sıra ${ }^{8,14}$, rPLU1, rPLU5 ve/veya rPLU3, rPLU4 (evrensel primerler) ve/veya rPLU5, rPLU6 ve rVIV1, rVIV2, rFAL1, rFAL2, rMAL1, rMAL2, rOVA1, rOVA2 (türe özgü primerler) ile nested PCR yöntemini uygulayan çalışmalar2,9,10,13,15-18 ve farklı ticari kitlerin ${ }^{13,14}$ kullanıldığı çalışmalar da mevcuttur. Çalışmamızda multipleks nested PCR yöntemi için Plasmodium cinsine özgü rPLU1, rPLU5 primerleri ve türe özgü rVIV1, rVIV2, rFAL1, rFAL2, rMAL1, rMAL2, rOVA1, rOVA2 primerleri, in-house Rt-PCR yöntemi için PL1473F18 ve PL1679R18 primerleri, ticari Rt-PCR yöntemi için Plasmodium spp. (18S ribozomal RNA geni) ve her bir alt tür için ayrı olmak üzere ticari kit (Genesig, İngiltere) kullanılmıştır. Multipleks nested PCR yöntemi altın standart olarak kabul edilmiştir.

Seçilen primerlerin saptama limiti değerlendirildiğinde, PL1473F18 ve PL1679R18 primerlerinin saptama limitinin 1 parazit/ $\mu$ kan olarak belirlendiği çalışmalar ${ }^{8}$, rPLU1, rPLU5 ve/veya rPLU3, rPLU4 ile rVIV1, rVIV2, rFAL1, rFAL2, rMAL1, rMAL2, rOVA1, rOVA2 primerlerinin kullanıldığı nested PCR'nin P.vivax için saptama limitinin 1-10 parazit/ $\mu \mathrm{l}$ kan, P.falciparum için 10-50 parazit/ $\mu \mathrm{l}$ kan, P.malariae için 50-100 parazit/ $\mu \mathrm{l}$ kan, P.ovale için 5-10 parazit/ $\mu$ l kan olarak belirlendiği çalışmalar9,10,15 ve rPLU5, rPLU6, FAL1, FAL2 primerleri ile nested PCR'nin saptama limitinin 0.05-3.6 parazit/ $\mu$ kan olarak belirlendiği çalışmalar ${ }^{13,16-18}$ olduğu görülmektedir. Çalışmamızda PL1473F18 ve PL1679R18 primerlerinin kullanıldığı in-house Rt-PCR yönteminin saptama limitinin klonlanmış P.vivax pozitif örnek için reaksiyonda 24 kopya (4.8 parazit/ $\mu$ l) olduğu saptanmıştır. PL1473F18 ve PL1679R18 primerleri ile Rt-PCR yönteminin tekli enfeksiyonların yanı sıra mikst enfeksiyonları da saptayabildiği bildirilmektedir ${ }^{8}$. Çeşitli çalışmalarda rPLU1, rPLU5 ve/veya rPLU3, rPLU4 (evrensel primerler) ve rVIV1, rVIV2, rFAL1, rFAL2, rMAL1, rMAL2, rOVA1, rOVA2 (türe özgü primerler) ile nested PCR'nin hem tekli hem de mikst enfeksiyonları belirleyebildiği bildirilmiştir ${ }^{2,15}$. Çalışmamızda pozitif olarak belirlenen kan örneklerinin tümü P.vivax olup, mikst enfeksiyon saptanmamıştır. 
Bir testin doğrulama testi olarak kabul edilmesi için özgüllüğünün yüksek olmaSı gereklidir. Seçilen primerler duyarlıık ve özgüllükleri açısından değerlendirildiğinde PL1473F18 ve PL1679R18 primerlerinin kullanıldığı Rt-PCR'nin P.vivax için duyarlılığının \%100, özgüllüğünün \%99.1, P.falciparum için duyarlılığının \%94.1, özgüllüğünün \%100 olarak belirlendiği bir çalışma7 ve rPLU1, rPLU5 ve/veya rPLU3, rPLU4 ile rVIV1, rVIV2, rFAL1, rFAL2, rMAL1, rMAL2, rOVA1, rOVA2 primerlerinin kullanıldığı nested PCR'nin duyarlılığının \%100, özgüllüğünün \%97.2 olarak belirlendiği bir başka çalışmanın ${ }^{19}$ olduğu belirlenmiştir. Nested PCR'nin mikroskobik incelemeye göre duyarlılık ve özgüllüğünün yüksek olması nedeniyle altın standart yöntem olarak kabul edildiği bir başka çaIışma da bulunmaktadır ${ }^{20}$. Çalışmamızda nested PCR yöntemi altın standart olarak kabul edildiğinde in-house Rt-PCR yönteminin duyarlıığı \%98, özgüllüğü \%97, ticari Rt-PCR yönteminin duyarlıığı \%97, özgüllüğü \%95 olarak belirlenmiştir.

PL1473F18 ve PL1679R18 primerlerinin kullanıldığı Rt-PCR'nin erime eğrisi analiziyle Tm değerleri arasında en az $1^{\circ} \mathrm{C}^{\prime}$ lik fark sağlayacak şekilde dört tür arasında ayrım yapmak için yeterli olduğu bildirilmiştir. Tm değerleri P.vivax için $79.0-81.0^{\circ} \mathrm{C}$, P.falciparum için $75.5-77.5^{\circ} \mathrm{C}$, P.malariae için $73.5-75.5^{\circ} \mathrm{C}$, P.ovale için $77.5-79.0^{\circ} \mathrm{C}$ olarak belirlenmiş$\mathrm{tir}^{8}$. Çalışmamızda aynı primerler kullanıldığında in-house Rt-PCR ile P.vivax pozitif örneklerin Tm değerleri 78-79, P.falciparum pozitif örneklerin Tm değerleri 75-75.5, P.malariae pozitif örneklerin Tm değerleri 74-74.5, P.ovale pozitif örneklerin Tm değerleri 76.5-77 olarak saptanmıştır (Şekil 1). Bu yöntem tek bir reaksiyonla parazitin tür ayrımının yapılması için yeterli ve uygun bulunmuştur. İlgili literatürle aynı primerleri kullanmamıza rağmen, elde edilen erime eğrilerindeki farklılıkların DNA alikotlarındaki tuz konsantrasyonlarının farklılığına bağlı olabileceği düşünülmüştür.

Rt-PCR yöntemi CT değerleri açısından değerlendirildiğinde genel olarak parazit yoğunluğu ile CT değeri arasında negatif bir ilişki bulunmakta, parazit yoğunluğu arttıkça CT değeri azalmakta ve daha erken pozitiflik gözlenmektedir ${ }^{17}$. CT değerlerinin düşük bulunması, uygulanan yöntemin DNA'yı daha iyi saptayabildiğini göstermektedir ${ }^{11,14}$. Çalışmamızda CT değerinin 35'in üzerinde olduğu örnekler negatif olarak kabul edildi. In-house Rt-PCR ile pozitif örneklerin CT değerleri 20.03-30.95 arasında, ticari Rt-PCR ile pozitif örneklerin CT değerleri ise 17.26-34.94 arasında saptandı. İki yöntemin CT değerleri karşılaştırıldığında ticari Rt-PCR ile parazitemi oranı yüksek örneklerin CT değerinin in-house Rt-PCR'den daha düşük olduğu, ancak parazitemi oranı düşük örneklerin CT değerinin in-house PCR'den daha yüksek olduğu belirlendi. Ticari Rt-PCR yöntemi ile dört örneğin yalancı negatif olarak belirlenmesinin nedeninin yüksek CT değerlerinden kaynaklandığı düşünülmüştür.

Kappa değeri (к), iki gözlemci arasındaki uyumun şansa bağlı kısmını düzelten bir uyum ölçüsüdür. Karşılaştırılan iki test arasındaki uyumun yüksek bulunması durumunda, yapılan değerlendirmeler güvenilir olarak kabul edilmektedir ${ }^{21}$. Uygulanan yöntemlerin birbiriyle uyumu değerlendirildiğinde rPLU1, rPLU5 ve/veya rPLU3, rPLU4 ile rVIV1, rVIV2, rFAL1, rFAL2, rMAL1, rMAL2, rOVA1, rOVA2 primerlerinin kulanıldığı iki nested 
PCR ve Rt-PCR yöntemleri arasında mükemmel uyum belirlenen çalışmalar olduğu belirlenmiştir ${ }^{2,10,15}$. Çalışmamızın sonucunda PL1473F18 ve PL1679R18 primerlerinin kullanıldığı in-house Rt-PCR ile ticari Rt-PCR yöntemi arasında yüksek düzeyde uyum (к: 0.953) saptanmıştır.

Multipleks nested PCR yöntemi aynı anda birçok türü tespit edebilmektedir. Ancak bu yöntem iki ardışık PCR amplifikasyonu gerektirdiğinden kısa sürede çok sayıda örneğin taranması için uygun değildir. Sonucun değerlendirilebilmesi için jel elektroforeze ihtiyaç duyulması gibi nedenlerle hem maliyeti yükselmekte hem de sonuç verme süresi uzamaktadır. Ayrıca, kontaminasyon riski de Rt-PCR'ye göre daha yüksektir. Kısa sürede çok sayıda örneğin taranması için daha hızlı ve daha düşük maliyetli bir moleküler yönteme ihtiyaç duyulmaktadır. Tek aşamalı ve erime eğrisi analizi ile tür ayrımına olanak veren inhouse Rt-PCR yöntemi daha az reaktif ve sarf malzemesi kullanımına ihtiyaç duymaktadır. Ayrıca kapalı bir sistem olması nedeniyle kontaminasyon riski de konvansiyonel PCR'ye göre oldukça düşüktür. Ticari Rt-PCR yöntemi ile sıtma şüpheli kan örneklerine öncelikle Plasmodium spp.'yi saptamaya yönelik primerler kullanılarak PCR, ardından pozitif çıkan örneklere tür ayrımı amacıyla her bir alt türü içeren primerler kullanılarak ikinci bir PCR yöntemi uygulanması gerekmektedir. Bu şekilde Plasmodium spp. pozitif olan her bir örnek için altı farklı PCR uygulanmakta, hem maliyet hem de tanı koyma süresi artmaktadır. Ayrıca bu yöntemin yalancı negatiflik oranı gözönüne alındığında negatif sonuç alınan örneklere doğrulama amacıyla nested PCR uygulanmasının da gerekli olduğu düşünülmektedir.

Sıtma şüphesi ile laboratuvarımıza gelen kan örneklerine uygulanan tanı algoritması, öncelikle mikroskobik inceleme ve hızlı tanı testleri uygulandıktan sonra tür ayrımı ve doğrulama amacıyla moleküler yöntemlerin uygulanması şeklindedir. Maliyet, tanı koyma süresi ve duyarlıık, özgüllük oranları birlikte değerlendirildiğinde in-house Rt-PCR yönteminin rutin hasta tanısında birinci tercih olarak düşünülebileceğine karar verilmiştir. Ayrıca negatif sonuç alınan örneklere, doğrulama amacıyla nested PCR uygulanmasının daha güvenilir sonuçlar için gerekli olduğu düşünülmüştür.

\section{ÇIKAR ÇATIŞMASI}

Yazarlar bu makale ile ilgili herhangi bir çıkar çatışması bildirmemişlerdir.

\section{KAYNAKLAR}

1. Alver O, Ener B. Bursa'da 2013-2014 yılları arasında sıtma epidemiyolojisi. Turk Hij Den Biyol Derg 2018; 75(1): 37-42.

2. Shokoples SE, Ndao M, Kowalewska-Grochowska K, Yanow SK. A multiplexed real-time PCR assay for malaria speciation with improved sensitivity for mixed infections. J Clin Microbiol 2009; 47(4): 975-80.

3. Zorbozan O, Pullukçu H, Atalay Şahar E, Karakavuk M, Can H, Tunalı V, et al. Mikroskopide atipik görünümlü dış kaynaklı iki sıtma olgusunda hızı test, serolojik ve moleküler yöntemlerin tanıya katkısının önemi. Mikrobiyol Bul 2017; 51(4): 396-403.

4. Özbilgin A, Topluoglu S, Es S, Islek E, Mollahaliloglu S, Erkoc Y. Malaria in Turkey: successful control and strategies for achieving elimination. Acta Trop 2011; 120: 15-23. 
5. https://www.who.int/malaria/publications/world-malaria-report-2015/report/en/

6. Farcas GA, Soeller R, Zhong K, Zahirieh A, Kain KC. Real-time polymerase chain reaction assay for the rapid detection and characterization of chloroquine-resistant Plasmodium falciparum malaria in returned travelers. Clin Infect Dis 2006; 42(5): 622-7.

7. Singh B, Bobogare A, Cox-Singh J, Snounou G, Abdullah MS, Rahman HA. A genus- and species specific nested polymerase chain reaction malaria detection assay for epidemiologic studie. Am J Trop Med Hyg 1999; 60(4): 687-92.

8. Mangold KA, Manson RU, Koay ESC, Stephens L, Regner MA, Thomson RB, et al. Real-time PCR for detection and identification of Plasmodium spp. J Clin Microbiol 2005; 43(5): 2435-40.

9. Stanis CS, Song BK, Chua TH, Lau YL, Jelip J. Evaluation of new multiplex PCR primers for the identification of Plasmodium species found in Sabah, Malaysia. Turk J Med Sci 2016; 46: 207-18.

10. Lau YL, Lai MY, Anthony CN, Chang PY, Palaeya V, Fong MY, et al. Comparison of three molecular methods for the detection and speciation of five human Plasmodium species. Am J Trop Med Hyg 2015; 92(1): 28-33.

11. Cnops L, Jacobs J, Van Esbroeck M. Validation of a four-primer real-time PCR as a diagnostic tool for single and mixed Plasmodium infections. Clin Microbiol Infect 2011; 17(7): 1101-7.

12. Gama BE, Silva-Pres FES, Lopes MNKR, Cardoso MAB, Britto C, Torres KL, et al. Real-time PCR versus conventional PCR for malaria parasite detection in low-grade parasitemia. Exp Parasitol 2007; 116(4): 427 32.

13. Kim JY, Goo YK, Ji SY, Shin HI, HanET, Hong Y, et al. Development and efficacy of real-time PCR in the diagnosis of vivax malaria using field samples in the Republic of Korea. PLoS One 2014; 9(8): e105871.

14. Hagen RM, Hinz R, Tannich E, Frickman H. Comparison of two real-time PCR assays for the detection of malaria parasites from hemolytic blood samples-short communication. European J Microbiol Immunol 2015; 5(2): 159-63.

15. Wang B, Han SS, Cho C, Han JH, Cheng Y, Lee SK, et al. Comparison of microscopy, nested-PCR, and real-time-PCR assays using high-throughput screening of pooled samples for diagnosis of malaria in asymptomatic carriers from areas of endemicity in Myanmar. J Clin Microbiol 2014; 52(6): 1838-45.

16. Ávila JG. Sensitivity of malaria diagnosis in blood samples by PCR assay: A comparison with microscopy. United States Army Center for Health Promotion and Prevention - West, Fort Lewis Division, 2005 (Erişim Adresi: https://pdfs.semanticscholar.org/73b2/0c93963b4847a5e4d0a4947d7fc88ee9b523.pdf).

17. Tran TM, Aghili A, Li S, Ongoiba A, Kayentao K, Doumbo S, et al. A nested real-time PCR assay for the quantification of Plasmodium falciparum DNA extracted form dried blood spots. Malar J 2014; 13: 393.

18. Lima GFMC, Levi JE, Geraldi MP, Sanchez MCA, Segurado AAC, Hristov AD, et al. Malaria diagnosis from pooled blood samples: comparative analysis of real-time PCR, nested PCR and immunoassay as a platform for the molecular and serological diagnosis of malaria on a large-scale. Mem Inst Oswaldo Cruz 2011; 106(6): 691-700.

19. Yentur Doni N, Yıldız Zeyrek F, Seyrek A. Detection of Plasmodium using filter paper and nested PCR for patients with malaria in Sanliurfa, in Turkey. Malar J 2016; 15: 299.

20. Perandin F, Manca N, Calderaro A, Piccolo G, Galati L, Ricci L, et al. Development of a real-time PCR assay for detection of Plasmodium falciparum, Plasmodium vivax, and Plasmodium ovale for routine clinical diagnosis. J Clin Microbiol 2004; 42(3): 1214-9.

21. Gözükara Bağ HG, Karabulut E, Alpar CR. 2X2 gözlü tablolarda gözlemciler/gözlemler arası uyumun değerlendirilmesi. Hacettepe Diş Hek Fak Derg 2010; 34(1-2): 46-52. 